J. Beerten, E. Laes, G. Meskens, and W. D'haeseleer, "Greenhouse gas emmissions in the nuclear life cycle: A balanced appraisal," Energy Policy, vol. 37, no. 12, pp. 5056 - 5068, Dec. 2009.

Digital Objective Identifier: 10.1016/j.enpol.2009.06.073

URL:

http://www.sciencedirect.com/science/article/pii/S0301421509005102

NOTICE: this is the author's version of a work that was accepted for publication in Energy Policy. Changes resulting from the publishing process, such as peer review, editing, corrections, structural formatting, and other quality control mechanisms may not be reflected in this document. Changes may have been made to this work since it was submitted for publication. A definitive version was subsequently published in Energy Policy, vol. 37, no. 12, Dec. 2009. 


\title{
Greenhouse gas emissions in the nuclear life cycle: A balanced appraisal
}

\author{
Jef Beerten $^{\mathrm{a}}$, Erik Laes ${ }^{\mathrm{b}}$, Gaston Meskens ${ }^{\mathrm{b}}$, William D'haeseleer ${ }^{\mathrm{c}, *}$ \\ ${ }^{a}$ K.U.Leuven Energy Institute, Division of Electrical Energy and Computer Architectures ,University of \\ Leuven (K.U.Leuven), Kasteelpark Arenberg 10 bus 2445, B-3001 Leuven, Belgium \\ ${ }^{b}$ Institute for Environment, Health and Safety, Belgian Nuclear Research Centre (SCK-CEN), Boeretang 200, \\ B-2400 Mol, Belgium
}

${ }^{c}$ K.U.Leuven Energy Institute, Division of Applied Mechanics and Energy Conversion, University of Leuven (K.U.Leuven), Celestijenenlaan 300 A, B-3001 Leuven, Belgium

* Corresponding author. Tel: +32-16-32-25-11; fax: +32-16-32-29-85

E-mail address: william.dhaeseleer@mech.kuleuven.be 


\section{Abstract}

In order to combat global warming, a detailed knowledge of the greenhouse gas emissions associated with different energy conversion technologies is important. For nuclear energy, greenhouse gas emissions result from the different process stages of the whole fuel cycle. A life cycle assessment offers the possibility to properly calculate these emissions. In the past, both indirect energy use and greenhouse gas emissions were studied by many researchers. Most of the studies result in low indirect emissions comparable to wind turbines. However, some of the studies in the literature obtain high results adding up to a significant fraction of the direct emissions from a CCGT.

In this paper, the greenhouse gas emissions resulting from the overall nuclear fuel cycle are analyzed by making a detailed comparison of the results from three different life cycle assessments. Hereby, the studies are chosen in order to reflect the range of results available in open literature. The studies under consideration result in indirect emissions of around $8 \mathrm{~g}$ $\mathrm{CO}_{2} / \mathrm{kWh}_{\mathrm{e}}, 58 \mathrm{~g} \mathrm{CO}_{2} / \mathrm{kWh}_{\mathrm{e}}$ and more than $110 \mathrm{~g} \mathrm{CO}_{2} / \mathrm{kWh}_{\mathrm{e}}$.

An explanation is given for these strongly varying results by analyzing the input data, assumptions and estimations made for the different process steps.

Keywords: Greenhouse-gas emissions, Life-cycle assessment, Nuclear 


\section{Introduction}

In the current debate, environmental constraints resulting from the reduction of greenhouse gas emissions put a still growing pressure on our energy system. From this point of view, it is important to know the emissions related to the different energy conversion technologies for electricity generation.

The operation of so-called 'emission-free' power plants like wind turbines, photovoltaic plants and nuclear power plants does not contribute to global warming. However, indirect greenhouse gas $(\mathrm{GHG})$ emissions result from the extraction and conversion of raw materials, the construction of the power plants and other process steps in the entire life cycle. A lifecycle assessment (LCA) is a proper tool to calculate the emissions related to the different steps in the life cycle.

For the LCA of nuclear power plants, the results of different studies available in the open literature contradict each other, as well as the conclusions drawn from them. Most of the studies show that the overall indirect emissions, i.e. associated with the mining and milling of the ore, the conversion to fuel elements, the construction of the nuclear power plant and the disposal of the waste are rather small and comparable to wind power plants. However, some studies suggest that these emissions are heavily underestimated, which would make it almost impossible for nuclear power to combat global warming in the future. The results of the studies largely depend upon the inputs, the assumptions and simplifications in different steps in the analysis, which can reflect a specific national context or which can be influenced by the viewpoint of the authors.

Recent attempts to summarize the results of different studies and to find an explanation for the strongly divergent results are already available in the literature. Fthenakis and Kim (2007) include low, intermediate and high results for lifetime GHG emissions from nuclear life cycles and conclude the biggest differences can be explained by different assumptions with respect to enrichment, construction and operation. However, detailed information on the input data for these process steps is lacking. The overview provided by Burkhardt et al. 
(2007) provides a comparison with other energy conversion technologies but does not reveal much detail on the different process steps in the nuclear life cycle. A more thorough review was performed by Lenzen (2008). Most recently, Sovacool (2008) calculated a mean value for the overall emissions by averaging the global results of 19 LCA studies forming a subset of, as stated by the author, "the most current, original and transparent studies" out of 103 studies. However, a critical assessment reveals that a majority of the studies representing the upper part of the spectrum are studies that can be traced back to the same input data and performed by the same author, namely Storm van Leeuwen. After careful analysis, it must be concluded that the mix of selected LCAs results in a skewed and distorted collection of different results available in the literature. Furthermore, since many studies use different energy mixes and other assumptions, averaging greenhouse gas emissions of those studies is no sound method to calculate an overall emission coefficients, as it gives no site-specific information needed for policy makers to base their decisions.

This paper aims to give a detailed picture of the greenhouse gas emissions in the different process stages of the nuclear fuel cycle by comparing the results of three different case studies, reflecting the range of results available in the literature. The greenhouse gas emissions are analyzed together with the indirect energy use since most of the emissions result from the use of energy in the different process stages. This paper aims to give an explanation for the deviations by recalculating the results using the same input data and assumptions as the original studies. The analysis of the different process steps in the life cycle will show that the main differences between the results are not only due to constraints and simplifications, but also due to estimates and assumptions.

The first chapter deals with the methodology, scope and a specification of the important parameters. Furthermore, the main results of the three case studies are summarized. In the second chapter the condensed energy and greenhouse gas intensities for the overall fuel cycle are recalculated in order to indicate the contributions of the different process stages to the overall result. A detailed comparison of the input data and assumptions will locate the major 
contributions to the overall results. Finally the influence of the different fuel mixes is considered.

\section{Methodology and information gathering}

This chapter provides an analysis of both the scope, contextual assumptions and main results of the three different representative studies selected for this work. In this comparative review, the nuclear life cycle under consideration is that of a Pressurized Water Reactor (PWR) without a recycling stage. In order to investigate the contribution of the different process steps to the overall result and to make a detailed comparison of the case studies, the consolidated results were recalculated using the same inputs and assumptions as the original studies.

Since a major part of the indirect greenhouse gas emissions in the nuclear life cycle are energy-related, energy requirements are compared as well in this study. Thereby, a distinction is made between electrical, thermal and total primary energy, respectively expressed in $\mathrm{kWh}_{\mathrm{el}}, \mathrm{kWh}_{\mathrm{th}}$ and $\mathrm{kWh}_{\mathrm{p}}$. Thermal energy is defined as the primary energy (e.g. oil, natural gas, coal) used for transport or heat generation. The total primary energy includes both thermal and electrical energy, in which electrical energy has to be converted to the corresponding primary energy using a conversion factor, reflecting the assumptions on the electricity generation mix.

The next parts will subsequently address the different studies, their scope and assesment methodology and the greenhouse gas emissions stated by the authors.

\subsection{Belgian study}

The first study has taken place in the context of a nation-wide $\mathrm{CO}_{2}$-project under the auspices of the former regulator (Control Committee for Electricity and Gas) and was ordered by the Belgian electricity producers. The overall study constitutes of two different parts, which were performed respectively by the Flemish Institute for Technological Research (VITO) and the University of Leuven. The first part undertaken by Torfs et al. (1998) calculates the primary energy use and greenhouse gas emissions associated with the 
delivery of relevant energy carriers to Belgian electricity producers. A short summary of the main results for the nuclear fuel cycle are included in the appendix of this paper since the original study is written in Dutch. Briefly, it concerns the energy use and emissions associated with the upstream part of the nuclear fuel cycle, i.e. starting from the mining of the ore up to the delivery of the fuel elements at the power plants. Within this part of the study, the authors calculate the direct energy use in the different process steps and the related greenhouse gas emissions. The indirect energy use and emissions associated with infrastructure and auxiliary materials used in the fuel cycle is estimated based on other literature data.

The second part of this study, undertaken by Voorspools et al. (2000), calculates the energy use and greenhouse gas emissions related to the construction, maintenance and demolition of so called 'emission-free' power plants, i.e. nuclear power plants, wind farms and photovoltaic plants. The results for the nuclear power plants are used in this comparative review.

The combination of both parts of the study does not take into account the temporary storage and final disposal of the radioactive waste. For the upstream part of the fuel cycle, Torfs et al. (1998) use Belgian data for the different process steps, completed with data from the ETH-database (Frishknecht et al., 1995). Voorspools et al. (2000) use real data obtained from the engineering office responsible for the construction of the Belgian nuclear power plants Doel 3/4 in order to calculate the energy use and greenhouse gas emissions related to the construction, maintenance and demolition of the power plant.

Both parts take into account different primary energy carriers in order to generate the thermal energy in the different processing steps. As will be shown later on in this work, this distinction is crucial in the calculation of greenhouse gas emissions. A European electricity mix is used for the electrical inputs in the different process steps, except for the electrical input of the gas diffusion plant in the enrichment phase. The fraction of the fuel enriched using diffusion technology is fabricated at the Eurodif facility in France which is directly fed by the Tricastin nuclear power plant. Therefore an all nuclear electricity input is used for the 
diffusion based enrichment fraction. Another part of the fuel is taken to be enriched via ultracentrifuge, for which a European electricity mix is used. Further details on this study can be found in the appendix.

\subsection{Storm van Leeuwen and Smith study}

The study performed by Storm van Leeuwen and Smith (2005) (abbreviated as SvL\&S) was ordered by the green parties in the European parliament to serve as a background document for a UN climate conference. On the one hand, the authors consider the potential of nuclear energy to cover the energy demand worldwide. On the other hand, the potential for the reduction of greenhouse gas emissions is investigated. The authors calculate greenhouse gas intensities for the present nuclear life cycle which are reasonably higher than other studies in the literature. In investigating the possibilities of nuclear power to combat global warming in the long term, the authors make use of data related to the extraction of leaner uranium ores, which makes the extraction stage both very energy- and greenhouse gas intensive. The figures show a nuclear fuel cycle consuming more energy than the overall electrical energy output over its lifetime when relying on lean ores in the long term. These results make the authors conclude that it is hardly possible for nuclear power to deliver a significant contribution to the world energy demand in the long term. Since its release, the results and conclusions have been subsequently questioned. The exchanges between Storm van Leeuwen and Smith and opponents are summarized by Lenzen (2008).

In the SvL\&S study, the results for both energy and greenhouse gas emissions are presented by means of break-even charts. In order to make a comparison with the other studies investigated in this paper, the results are converted to energy and greenhouse gas intensities using the same input data and assumptions.

\subsection{Australian study}

The third study compared in this paper is the study performed by Lenzen et al. (2006), ordered by the prime minister of Australia in order to investigate the future possibilities for nuclear power to contribute to a greenhouse gas reduction for Australia. The calculations are 
based on a hypothetic fuel cycle in which the country relies on facilities abroad for the fabrication of the fuel elements in the short term. The extensive literature overview and main results of the analysis are presented as well in the review paper by Lenzen (2008).

In 2003, Australia's electricity generation was very carbon intensive with ca. $92 \%$ of the electricity produced by fossil power plants, mainly produced by coal fired plants (ca. $77 \%$ of the yearly generated electrical energy) (IEA, 2005). Although Australia is the second largest producer of uranium after Canada (WEC, 2007), the country does not have any commercial nuclear power plants nor do they have facilities to produce nuclear fuel elements. Because of the high carbon intensity of the Australian economy, the authors make use of an 'all coal energy economy', with coal fired plants for electricity generation and coal as an energy carrier to generate thermal energy. Within this study, Lenzen et al. (2006) make use of the literature overview by Storm van Leeuwen and Smith (2005). The input data correspond to those cited by SvL\&S for some process steps in the upstream part of the fuel cycle. However, the results obtained by the authors in terms of $\mathrm{g} \mathrm{CO}_{2}$-eq./kWh are smaller than those observed in the SvL\&S study.

\section{$2.4 \quad$ Scope and assessment method}

From previous analyses presented in the literature, it was found that the assessment method used to calculate the energy and greenhouse gas intensity is a major cause for diverging results. A detailed description of the different assessment methods and their effect on the overall result is presented in Lenzen et al. (2006). Although a high emphasis is recently put on GHG emissions, the analysis is still carried out using an energy analysis. A first method to perform such an energy analysis is a process chain analysis (PCA), in which the energy requirements of the main production processes are assessed in detail. Regarding a PCA, Lenzen et al. (2006) point out that it leads to a systematic error, due to the truncation of the system boundary. A second method, the input-output analysis (IOA), starts from monetary cost data which are assigned to the different sectors defined by the input-output tables. In order to combine the strengths of PCA (detailness) and IOA (completeness), hybrid 
input-output analysis (H-IOA) techniques were developed. A simplified method based on an average energy intensity (AEI), in which the overall monetary cost is multiplied with an economy-wide energy intensity, is used by Storm van Leeuwen and Smith (2005) for a number of process steps. Apart from the assessment method, the scope of the study is another important factor determining the overall result. Not all of the studies do take into account every single process step. Table 1 addresses both the scope of the different studies and the assessment method for the different process steps.

In the Belgian study, Torfs et al. (1998) use a PCA for the different steps in the nuclear life cycle. Concerning the system boundaries, only the direct energy use by the different processes is considered. An estimation based on literature data is provided for the overall energy involved with auxiliary materials and infrastructure. In the second part of the study, Voorspools et al. (1998) perform a PCA as well as an IOA for the construction phase. For the operation and maintenance of the plant, a H-IOA is used, whereas the energy related to the decommissioning is calculated using a PCA. The temporary storage and final disposal of the waste was not taken into account, since it was not within the scope of this study. The clean-up of the mine site was not taken into account due to lack of data.

Storm van Leeuwen and Smith (2005) use the results of previous studies for the upstream part of the fuel cycle. The data provided by Rotty et al. (1975) were calculated using a HIOA. For the milling of the ore and the enrichment phase, SvL\&S add energy intensities from different studies, which makes it hard to address the assessment method. For the downstream part of the life cycle, AEI methods are used. SvL\&S do not take into account the transport between the different processing facilities.

Lenzen et al. (2006) include all process steps, except for the clean-up of the mine site, and also use previously published studies to make their energy and GHG assessment. The majority of the data for upstream part of the life cycle are provided by the hybrid IOA performed by Rotty et al. (1975). Averaged data from various sources was used for the mining \& milling stage, as well as for the enrichment. The construction energy of the power 
plant is calculated using an IOA, whereas the assessment for other processes is based on (simplified) IOA or PCA (Table 1).

\subsection{Assumptions and main results}

Whereas the Belgian study makes a distinction between the different forms of primary energy used in the different processes (e.g. natural gas, oil, gasoline), the other studies only make a distinction between thermal and electrical energy. This makes the results highly sensitive to contextual assumptions concerning the energy carriers used for the generation of thermal and electrical energy in the different processing steps. The different parameters in this comparative study are left unaltered in order to obtain the same results as the studies under consideration. Table 2 summarizes the different assumptions. Additional assumptions are printed in italic.

In their study, Storm van Leeuwen and Smith (2005) make a distinction between different ore grades and types. Therefore, two results are included, representing both the actual situation (soft ore $-0.15 \% \quad \mathrm{U}_{3} \mathrm{O}_{8}$ ) and a result which can serve as a 'worst case' scenario (hard ore $-0.01 \% \mathrm{U}_{3} \mathrm{O}_{8}$ ), since it represents the lowest ore grade used by SvL\&S to make future prospects. SvL\&S add electrical and thermal energy without conversion in their break even charts, which is against convention and is basically incorrect. Therefore the conversion factor from Torfs et al. (1998) is used to convert electrical to primary energy. The authors make use of nuclear electricity and oil in their break-even charts for greenhouse gasses, which is reflected by the emission coefficients for Storm van Leeuwen and Smith (2005). These coefficients only include direct emissions. In the Belgian study (Torfs et al., 1998; Voorspools et al., 1998) a distinction is made between different energy carriers for thermal energy. Therefore, no single GHG-intensity coefficient is defined for the thermal energy in Table 2 for this study. The carbon intensive economy used by Lenzen et al. (2006) is reflected by the high GHG coefficients.

The GHG emissions for the upstream part of the fuel cycle calculated by Torfs et al. (1998) range from $4.7-13.6 \mathrm{~g} \mathrm{CO}_{2} / \mathrm{kWh}_{\mathrm{e}}$, dependent on the assumptions for the electrical 
input for the gas diffusion stage. $4.7 \mathrm{~g} \mathrm{CO}_{2} / \mathrm{kWh}_{\mathrm{e}}$ is used as a best estimate for Belgium. For the construction, operation and demolition of the power plant, Voorspools et al. (2000) calculated a range of $1.8-4 \mathrm{~g} \mathrm{CO}_{2} / \mathrm{kWh}_{\mathrm{e}}$. The combination of both studies results in results in a range of $7-18 \mathrm{~g} \mathrm{CO}_{2} / \mathrm{kWh}_{\mathrm{e}}$, with $7.7 \mathrm{~g} \mathrm{CO}_{2} / \mathrm{kWh}_{\mathrm{e}}$ as a best estimate for Belgium. From the input data provided by Storm van Leeuwen and Smith (2005), results ranging from 117.2 to $337.4 \mathrm{~g} \mathrm{CO}_{2} / \mathrm{kWh}_{\mathrm{e}}$ are found, dependent on the ore grade and ore type. Lenzen et al. (2006) provide greenhouse gas emissions ranging from $10-130 \mathrm{~g} \mathrm{CO}_{2} / \mathrm{kWh}_{\mathrm{e}}$ with $57.7 \mathrm{~g}$ $\mathrm{CO}_{2} / \mathrm{kWh}_{\mathrm{e}}$ as a best estimate for Australia.

\section{In-depth comparison of the results}

This section aims to give a detailed analysis of the results for the process steps by which the strong deviation in the final results can be explained. Subsequently, the different studies are compared. Table 3 summarizes the breakdown of the calculated greenhouse gas emissions for the different process steps in the nuclear life cycle. Table 4 summarizes the breakdown of the energy use for the different process steps.

\subsection{Mining, milling and recovery of the mine}

Uranium is mined in three different ways. Underground mining (UGM) and open pit mining (OPM) are the traditional techniques. In situ leaching (ISL), a method in which an acid solution is injected in the soil in order to dissolve the uranium which can be extracted afterwards, is used more and more. However, analyzing the input data reveals that none of the investigated studies takes ISL into account in a proper manner. In some mines, uranium is mined together with other metals, which makes it economically feasible to mine lower ore grades, since the monetary costs and energy use can be allocated between the different metals. After the mining, the ore is transported to the milling plant which is located close to the mine in order to avoid large transport distances. Here, the ore is milled and concentrated using a chemical dissolving process. The output of the milling plant is uranium concentrate ("yellow cake"). After the mine is closed, the mine site is restored. This recovery is discussed here as well. 
The energy use for the mining and milling stage per $\mathrm{kg}$ ore extracted is provided in Table 5. Torfs et al. (1998) consider only direct energy and related GHG emissions. The results do not take into account the energy associated with infrastructure and raw materials used in the fuel cycle. The data for this process stages were obtained from the ETH-database (Frishknecht et al., 1995) in which diesel is used for the mining (machines, supply of auxiliary materials and removal of debris) and natural gas and diesel for the milling of the ore. ISL and uranium as a byproduct are treated as OPM and UGM respectively by lack of data, resulting in $62 \%$ OPM and 38\% UGM. The study makes use of an ore grade of $0.2 \%$ $\mathrm{U}_{3} \mathrm{O}_{8}$, which is comparable to the $0.15 \%$ used for the other studies. The study takes into account a loss of $4.8 \%$ in the milling stage. The recovery of the mine site is not included in this study due to lack of relevant data.

Storm van Leeuwen and Smith (2005) make use of the energy data provided by Rotty et al. (1975) for the mining of the ore. This study investigates the energy expenditures of American uranium mines in the beginning of the 70's, using a mix of 60\% OPM and $40 \%$ UGM. These data include both the direct energy use and the energy associated with chemicals and materials. No correction is made for energy efficiency improvements and a shift in the shares of the different mining techniques since the 70's. Rotty et al. (1975) mention two different ore types with different energy intensities, namely 'ore' and 'shale'. The energy expenditures associated with these different ore types are respectively $0.4 \mathrm{MJ}_{\mathrm{p}} / \mathrm{kg}$ ore and $1.37 \mathrm{MJ}_{\mathrm{p}} / \mathrm{kg}$ ore, according to Lenzen (2008). The energy intensity used by SvL\&S closely resembles that of shale, but no mention is made concerning the lower energy intensity for ore. SvL\&S also provide a rough impression of the energy intensity for ISL, and assume ISL to take the same energy requirements as OPM. This approximation was also used by Torfs et al. (1998) due to lack of data on ISL. However, this is only an estimation, which might lead to a skewed representation. For the milling stage, SvL\&S make a distinction between soft and hard ores with energy inputs from ERDA (1976) for soft ore and from Kistemaker $(1975,1976)$ for hard ores. The latter studies calculated the energy used in South-African mines for hard, low quality ores and includes the energy associated with 
chemicals used in the milling process. Furthermore, an additional indirect energy input from Rotty et al. (1975) is added for the hard ores to account for the capital goods. The energy requirements for the milling of hard ores is thus obtained by adding the inputs from different studies. This leads to very high energy inputs when compared to the other studies (Table 5). The efficiency of the milling step is taken into account by SvL\&S using a regression formula based on literature data. According to this regression formula, the extraction yield of the milling stage for an ore grade of $0.15 \% \mathrm{U}_{3} \mathrm{O}_{8}$ equals $94 \%$, which is comparable to the extraction yield used by Torfs et al. (1998). However for low ore grades $\left(0.01 \% \mathrm{U}_{3} \mathrm{O}_{8}\right)$ the extraction yield is only about $70 \%$. This low extraction yield is an important factor in the large energy and greenhouse gas intensity for the mining and milling stage when a low ore grade is considered (Table 3, Table 4). The data used by SvL\&S in constructing the regression formula consist of both experimental and hypothetical values. For ore grades lower than $0.01 \%$, only hypothetic data are mentioned in the literature overview by SvL\&S. In constructing the regression formula, the experimental data for ore grades lower than $0.05 \%$ are excluded because these values deviate too strongly from the other experimental points. Therefore, the extraction yield for a low ore grade of $0.01 \%$ mainly results from an interpolation between hypothetical data with large associated uncertainty. Although the extraction yield in all of the three studies is approximately the same when considering current day ore grades $(0.15-0.2 \%)$, the results for low ore grades become more and more dependent on the hypothetical data used. Using the regression formula for ore grades lower than about $0.05 \%$ comes down to an interpolation between hypothetic data points.

Furthermore, SvL\&S put forward a procedure for the clean-up of the mine site based on a hypothetical model. Hereby, the mine tails are mixed with limestone (to neutralize the acids) and phosphates (in order to immobilize the radioactive nuclides). This mix is sandwiched in a next step between two layers of betonite. The energy involved (per unit of mass) is estimated to be the fourfold of the mining of the ore. The estimated mass of this waste is taken the double of the tailing mass. It must be stressed that this proposed hypothetical procedure is does not correspond to methods described in literature. The results from Table 3 
indicate a large contribution to the overall GHG emissions for the recovery based on this hypothetic model when the results for the lowest ore grades $\left(0.01 \% \mathrm{U}_{3} \mathrm{O}_{8}\right)$ are considered. The mining and milling of the ore, together with the clean-up of the mine site, forms a large contribution to the overall result when low ore grades are considered (approximately 70\% of the overall energy use and GHG emissions). These high numbers result from the high energy intensities used for the mining and milling of hard ores, combined with a very low extraction yield and the hypothetical model put forward for the clean-up of the mine site on the other hand.

The data used by Lenzen et al. (2006) for this process step are obtained from the literature overview provided by Storm van Leeuwen and Smith (2005), combined with specific data from Australian mines in which other metals are being mined, since the processes involved are basically the same as these of other metals. The share of the different mining techniques is not provided for these data. It was not possible to recalculate the averaged values (Table 5) used by Lenzen et al. (2006) since no additional information is provided to make the distinction between electrical and thermal energy. The extraction yield is taken into account by the regression formula introduced by SvL\&S, which is discussed above. It was found by recalculating the results that Lenzen et al. (2006) use this formula as a mining yield (directly after the mining stage), whereas SvL\&S use it as a mining and milling yield. This results in a small underestimation of the energy requirements for the milling stage in Lenzen et al. (2006). The influence on the overall result is relatively small, since an ore grade of $0.15 \%$ results in a loss of $6 \%$ which should be taken into account for the milling stage.

\subsection{Conversion}

The uranium concentrate is converted into $\mathrm{UF}_{6}$. This conversion is performed using a number of consecutive steps. A purification removes neutron absorbing material. The thermal and electrical energy inputs used by Torfs et al. (1998) were obtained from the ETHdatabase (Frishknecht et al., 1995) and amount to $700 \mathrm{MJ}_{\mathrm{th}} / \mathrm{kg} \mathrm{U}$ in the form of natural gas and $37 \mathrm{MJ}_{\mathrm{e}} / \mathrm{kg} \mathrm{U}$ in the form of electricity respectively. Both Storm van Leeuwen and Smith 
(2005) and Lenzen et al. (2006) make use of the data provided by Rotty et al. (1975), which are $1425 \mathrm{MJ}_{\mathrm{th}} / \mathrm{kg} \mathrm{U}$ and $52.8 \mathrm{MJ}_{\mathrm{e}} / \mathrm{kg} \mathrm{U}$. Lenzen et al. (2006) mention a conservative approach in choosing these data, which are amongst the largest in the literature overview by SvL\&S.

\subsection{Enrichment}

The concentration of the fissile U-235 isotope in natural uranium is only $0.71 \%$, whereas most reactors need a concentration of about $3-5 \%$ to become critical. Therefore the gaseous $\mathrm{UF}_{6}$ leaving the conversion plant has to be enriched in U-235. Mainly two industrial processes are considered. With the gaseous diffusion process, the gaseous $\mathrm{UF}_{6}$ is forced through a membrane. Due to the mass difference of the isotopes, the resulting stream is slightly enriched in U-235. In the ultracentrifuge process the heavier ${ }^{238} \mathrm{UF}_{6}$ moves towards the outer sides of the centrifuge. An axial stream removes the inner fraction which is slightly enriched in U-235. Dependent on the production technique used, the enrichment process may represent a major part of the total energy needs. The gaseous diffusion technology is far more energy intensive than the ultracentrifuge technique. Table 6 lists the energy intensities for both the gaseous diffusion and the ultracentrifuge technology used in the different studies.

The total energy intensity stated by Torfs et al. (1998) is significant, since it assumes a large share for the energy-intensive diffusion technology. The primary energy carriers used for thermal energy generation are oil for the gaseous diffusion in the Eurodif-plant (France) and natural gas for the ultracentrifuge in the Urenco-plants (Germany, Netherlands, UK), according to the ETH-database (Frischknecht et al., 1995). The electricity used in the gaseous diffusion plant Eurodif, is produced by the nuclear power plant of Tricastin, which directly feeds the production plant. Therefore, this energy is almost free of $\mathrm{CO}_{2}$-emissions. The GHG intensity also includes the emissions of CFC's, which contribute substantially to the total result. 
Storm van Leeuwen and Smith (2005) make use of data for gaseous diffusion by ERDA (1976) which is the largest energy input in their literature overview. For ultracentrifuge, a distinction is made between 'direct energy costs' (from Kistemaker, 1975) and 'operational costs' (obtained from Rotty et al., 1975). The direct energy costs are among the highest values given in the literature overview by SvL\&S. The operational costs associated with centrifuge are estimated to be the double of those calculated by Rotty et al. (1975) which are for gaseous diffusion. Despite the high energy intensity used by SvL\&S, the GHG intensity is very small, due to the nuclear electricity input.

Lenzen et al. (2006) use averaged values from different studies, provided in their literature overview. It is impossible to verify the energy inputs due to lack of data on the share of electrical and thermal energy. The GHG emissions constitute a major part in the overall emissions, which is caused by the coal-based background economy.

Table 6 predicts the largest energy intensity for the study undertaken by Torfs et al. (1998). Table 4, however, shows the largest results for SvL\&S, which is mainly caused by a higher Seperation Work Unit (SWU), due to a higher enrichment fraction $\mathrm{x}_{\mathrm{p}}$, shown in Table 2.

The thermal energy stated by Torfs et al. (1998) is significantly smaller than the other studies, because only direct energy use involved. The results for ultracentrifuge by SvL\&S depend on an estimation based on data for diffusion, which may not reflect the real energy use.

\subsection{Production of the fuel elements}

The enriched $\mathrm{UF}_{6}(3-5 \% \mathrm{U}-235)$ leaving the enrichment plant is converted to $\mathrm{UO}_{2}$ which is sintered into cylindrical pellets. These pellets are stacked into Zircalloy tubes, which are arranged in a rectangular configuration forming fuel elements.

Torfs et al. (1998) use data from the ETH-database (Frischknecht et al., 1995), which states a thermal energy of $80 \mathrm{MJ}_{\mathrm{th}} / \mathrm{kg} \mathrm{U}$ in the form of heating oil and $80 \mathrm{MJ}_{\mathrm{e}} / \mathrm{kg} \mathrm{U}$ of electrical energy. These data only include direct energy inputs. Both Lenzen et al. (2006) and 
Storm van Leeuwen and Smith (2005) use data provided by Rotty et al. (1975) . These figures are $2708 \mathrm{MJ}_{\mathrm{th}} / \mathrm{kg} \mathrm{U}$ and $1084 \mathrm{MJ}_{\mathrm{e}} / \mathrm{kg} \mathrm{U}$ and include direct energy inputs, construction energy and energy related to the use of auxiliary materials. The data are amongst the highest values in the literature overview provided by SvL\&S. Although the results differ to a large extent, the overall contribution of this process step to the overall energy use and GHG emissions is rather small.

\subsection{Transport}

The transport between the different process steps was taken into account by Torfs et al. (1998) and Lenzen et al. (2006). Because of the large energy densities involved with the nuclear fuel, the overall contribution to the greenhouse gas intensities is rather small (Table 3). Torfs et al. (1998) take into account the transport between the different stages in the upstream part of the fuel cycle. Because of the lack of an Australian nuclear fuel infrastructure, Lenzen et al. (2006) make use of facilities in Europe and USA. The latter study also takes into account the transport of the waste, which is not accounted for by Torfs et al. (1998). The contribution of this process step to the overall results is negligible.

\subsection{Construction of the power plant}

In the literature, mainly two different calculation methods are used regarding the energy related to the construction stage: a process chain analysis (PCA) and an input-output analysis (IOA). The results on a $\mathrm{kWh}_{\mathrm{e}}$-base are largely dependent on the lifetime and capacity factor, which are different for the three studies. Therefore, Table 7 makes a comparison per $\mathrm{GW}_{\mathrm{e}}$ installed power.

Voorspools et al. (2000) include two results for the indirect energy use and associated GHG emissions calculated by a PCA and IOA, which are respectively based on material data and cost data from the engineering office which was responsible for the Belgian nuclear power plants Doel 3/4. The energy intensities per tonne of material used in the PCA were obtained from the ETH-database (Frischknecht et al., 1995). In a last step the authors use actualized Belgian input-output tables in order to make a conversion from raw materials to 
finished products. These input-output tables are also used for the IOA. The authors stress that IOA leads to an overestimation for the construction energy of a nuclear power plant, since components for nuclear applications are much more expensive because of safety related issues. However, these high safety demands only result in a small increase of the energy involved. The PCA leads to a small underestimation, because in the final step, when the conversion from raw materials to final products is made, the method makes use of an average end product of the different sectors. Therefore this method does not take into account a higher energy use for materials used in a nuclear power plant. The overall result in Table 3 and Table 4 is calculated using the average of both PCA and IOA.

Lenzen et al. (2006) make use of an IOA performed by Chapman (1975), which is amongst the highest values in their literature overview. The electrical energy is assumed to constitute $10 \%$ of the total energy requirements, according to data provided by Rotty et al. (1976). The energy requirements are comparable to the IOA performed by Voorspools et al. (2000).

Table 3 shows a large contribution to the overall GHG emissions for the construction phase in the study undertaken by Storm van Leeuwen and Smith (2005). SvL\&S start from the monetary costs associated with the construction of American nuclear power plants. Thereafter, the related energy use is calculated in three approximate ways with a large associated uncertainty, mainly caused by the large range in monetary costs $(1.4-6 \mathrm{G} \$ 1982$ $\left./ \mathrm{GW}_{\mathrm{e}}\right)$.

In their first method, which is referred to as a simplified IOA by SvL\&S, they multiply an average cost of $3.7 \mathrm{G} \$_{1982} / \mathrm{GW}_{\mathrm{e}}$ with an average energy intensity $\left(83.8 \mathrm{MJ} / \$_{1967}\right)$ of the 'new construction' sector, provided by Bullard et al. (1978). The average cost data are first converted to the year 1967 by taking into account the monetary deflation using the consumer price index. SvL\&S do not take into account the improved energy-efficiency, but argue that the decrease in energy requirements is mainly offset by the increase due to a higher complexity resulting from more stringent safety requirements. This method results in an thermal and electrical energy expenditure of respectively $24598 \mathrm{GWh}_{\mathrm{th}} / \mathrm{GW}_{\mathrm{e}}$ and 5125 
$\mathrm{GWh}_{\mathrm{e}} / \mathrm{GW}_{\mathrm{e}}$ with very large uncertainty ranges of $9195-40000 \mathrm{GWh}_{\mathrm{th}} / \mathrm{GW}_{\mathrm{e}}$ and $1915-$ $8333 \mathrm{GWh}_{\mathrm{e}} / \mathrm{GW}_{\mathrm{e}}$. These ranges reflect the large range of cost data $\left(1.4-6 \mathrm{G} \$_{1982} / \mathrm{GW}_{\mathrm{e}}\right)$.

In their second method, the same monetary costs are converted to the year 2000 to account for monetary inflation. After this conversion the monetary costs are multiplied with the global energy intensity of the overall economy $\left(10.64 \mathrm{MJ} / \$_{2000}\right)$, per unit of Gross National Product (GNP), multiplied by a correction factor 1.16, provided by Bullard et al. (1978), to get a good approximation for the 'new construction' sector. This method results in a thermal and electrical energy expenditure of $18621 \mathrm{GWh}_{\mathrm{th}} / \mathrm{GW}_{\mathrm{e}}$ and $3879 \mathrm{GWh}_{\mathrm{e}} / \mathrm{GW}_{\mathrm{e}}$, with large uncertainty ranges of $7126-30345 \mathrm{GWh}_{\mathrm{th}} / \mathrm{GW}_{\mathrm{e}}$ and $1485-6322 \mathrm{GWh}_{\mathrm{e}} / \mathrm{GW}_{\mathrm{e}}$ respectively.

The third method is referred to as a process analysis in the literature overview by Lenzen et al. (2006). In this method, SvL\&S convert the total mass of the construction to an energy requirement, using a correlation which is derived from a graphical presentation on 1967 energy expenditures provided by Roberts (1982). It should be stressed that this assessment method differs to a large extent from the detailed process analysis performed by Voorspools et al. (2000). Instead, it shows a lot of similarities with the previously discussed AEI methods. The correlation used by SvL\&S relates the cost per unit of mass to the energy per unit of mass. Analyzing Roberts (1982) reveals that this correlation was set up using 50 out of 400 products identified by the input/output table for the USA. Using the same range of cost data as with the previous methods and a material input of $516 \mathrm{kt}$, this results in an overall energy expenditure of $26944 \mathrm{GWh}_{\mathrm{p}} / \mathrm{GW}_{\mathrm{e}}$, with a very large uncertainty range of $12500-39444 \mathrm{GWh}_{\mathrm{p}} / \mathrm{GW}_{\mathrm{e}}$. No distinction is made between thermal and electrical inputs.

In their final calculations, the method with the smallest result was chosen (method 2), in order not to overestimate the energy use, as stated by the SvL\&S. However, the calculated energy intensity is higher than those obtained by detailed IOAs or PCAs in the literature, according to the overview provided by Lenzen (2008). According to SvL\&S, it would not be meaningful to calculate the results in a more detailed way, because of the large range in monetary costs. 
Regarding this calculation method, three major critiques can be formulated. As stated by Lenzen et al. (2006), "National average energy and greenhouse gas intensities - calculated by dividing national energy consumption and greenhouse gas emissions by GDP - can only be applied to expenditures that are part of Gross National Expenditure (GNE). The costs of building a nuclear power plant are not part of GNE, they form part of intermediate demand." Secondly, this average energy intensity based on a total economy and corrected for to represent the new construction sector may not be representative for the construction of a nuclear power plant (Lenzen et al., 2006). Since a substantial part of the costs are not energy related, but due to administration, planning, licensing and legal affairs, the multiplication of the total monetary cost with an average energy intensity results in a substantial overestimation. As stated by SvL\&S, the monetary costs reflect a large range. However, a detailed IOA has to be performed in order to indicate the amount of energy related costs. Furthermore, the conversion factor used to take into account the new construction sector dates from 1978 and therefore may have changed considerably.

Regarding the third method, Lenzen et al. (2006) conclude from their literature overview that the material inventory is realistic, but the related energy expenditures calculated by SvL\&S are far higher than the results obtained by other PCA in the literature. In this comparative review, it was found that the main reason for the large result is due to the assessment method, which in fact shows a lot of similarities with the AEI methods. Contrary to the PCA by Voorspools et al. (2000), SvL\&S do not use this inventory to calculate the energy expenditure related to the fabrication of the different materials as described above. Instead, they only use the overall mass of the power plant and the large range of cost data. From these figures, the energy per unit of mass is deducted using a correlation formula, which was not specifically set-up for nuclear power plants, but derived from 50 goods which were available in value and energy per unit mass and defined by the USA input-output tables from the yearv1967. Therefore, it can be questioned to what extend this correlation provides a useful tool to make a correct assessment of the energy expenditures starting from a single cost figure and the overall mass of a nuclear power plant. Within their study, SvL\&S also 
use the energy intensity of the construction per unit mass further on in the downstream part of the life cycle.

\subsection{Operation, maintenance and refurbishment $(O M \& R)$}

Voorspools et al. (2000) take into account refurbishments over the total lifetime of the power plant. The operational activities are not considered. To calculate the energy intensity, both PCA and IOA were used, dependent on the availability of material and monetary cost data for Doel 3/4. The results are low when compared to the other studies but they are in the order of the energy related to the construction as calculated by a PCA.

With Lenzen et al. (2006) OM\&R account for approximately $24 \%$ of the total energy use. This result was calculated using the costs associated with the operation of the power plant, provided by Hewlett (1992). Thereafter, these costs were split into wages, assurances, administration and technical services which were multiplied with energetic intensities $(\mathrm{MJ} / \$)$. This procedure results in a yearly energy expenditure of $10 \mathrm{GWh}_{\mathrm{el}}$ of electricity and $270 \mathrm{GWh}_{\mathrm{th}}$ of thermal energy for a PWR with a capacity of $1 \mathrm{GW}_{\mathrm{e}}$. No explanation is given for the substantial share of OM\&R. This figure is amongst the highest values in their literature overview, which provides a range from $79-889 \mathrm{GWh}_{\mathrm{p}} / \mathrm{year}$ for a $1000 \mathrm{MW}$ PWR, with 79 and $889 \mathrm{GWh}_{\mathrm{p}} /$ year as outliers based on AEI. With these outliers excluded, this results in a range of $112-242 \mathrm{GWh}_{\mathrm{p}} /$ year with $213 \mathrm{GWh}_{\mathrm{p}} /$ year as an average value, which is lower than the $301 \mathrm{GWh}_{\mathrm{p}} /$ year used by Lenzen et al. (2006).

Storm van Leeuwen and Smith (2005) use monetary cost data (100 M\$/year) from Blok and Hendriks (1989), which are expressed as a percentage (2.8\% per full-power year) of the construction costs. For the refurbishments, another $50 \%$ of the construction costs is considered over 24 full-power years, resulting in an additional $2 \%$ and an overall OM\&R cost equal to $4.8 \%$ of the construction cost. These costs are multiplied with the same energetic intensities used in the construction phase, resulting in $993 \mathrm{GWh}_{\mathrm{th}} /$ year and 90 $\mathrm{GWh}_{\mathrm{e}} /$ year for a full-power year. In recalculating the study, it was found that a yearly expenditure of only $3 \%$ of the construction energy is used in the final calculations, resulting 
in $617 \mathrm{GWh}_{\mathrm{th}} /$ year and $58 \mathrm{GWh}_{\mathrm{e}} /$ year for a full-power year. It is not clear from the study why this value deviates from the one put forward in their analysis. The energy expenditure used by SvL\&S is the highest value cited in the literature overview provided by Lenzen (2008). Since the expenditures are related to the construction phase, the same critique is applicable.

\subsection{Temporary storage}

The fuel elements leaving the reactor are transferred to a temporary storage room in the proximity of the reactor in order to lower the activity of the fission products by radioactive decay. The heat produced by the decay of the fission products has to be removed. Both dry storage and wet storage are possible. Also for the low and intermediate level waste (respectively LLW and ILW), a temporary storage can be taken into account.

Another type of temporary storage that is considered in two of the studies under discussion, is the storage associated with the dismantling of the power plant. When the reactor is shut down, final dismantling can be postponed in order to lower the radioactivity of contaminated parts. The energy and greenhouse gas emissions associated with this waiting period are discussed here as well, since can be seen as a temporary storage of the reactor building.

Voorspools et al. (2000) do not consider the temporary storage of the spent fuel. For the decommissioning stage a waiting period of 60-70 years is assumed. However, no energy use is calculated for this waiting period.

Lenzen et al. (2006) use energy inputs calculated by the Australian Coal Association (ACA, 2001) concerning the temporary storage of HLW leaving the reactor. They mention a conservative approach in choosing this rather large value. This total energy use from ACA (2001) is converted to energetic intensities per unit mass, based on 25 tonne of fuel elements (Heinloth, 1997) leaving the nuclear reactor annually. The figures obtained are 600 $\mathrm{MWh}_{\mathrm{th}} /$ tonne waste and $80 \mathrm{MWh}_{\mathrm{th}} /$ tonne waste. Lenzen et al. (2006) also use these figures for LLW and ILW. Table 8 shows the break-up of total energy and greenhouse gas 
expenditures for the different process stages in which radioactive waste is produced. The structural materials include the tubes of $\mathrm{ZrO}_{2}$ surrounding the cylindrical $\mathrm{UO}_{2}$ pellets. The largest contribution results from the decommissioning of the power plant. Since the majority of this waste is LLW/ILW, it concerns energy expenditures calculated for HLW extrapolated to a large amount of LLW, which results in an overestimation.

Storm van Leeuwen and Smith (2005) take into account temporary storage, conditioning and final disposal. Temporary storage is only taken into account for fuel elements leaving the reactor. SvL\&S make use of a method similar to the one used with the construction of the power plant: the monetary costs of the storage facilities are multiplied by a global energy intensity (in $\mathrm{MJ} / \$$ ) and converted to an energy intensity per tonne of waste produced. The same critique is therefore applicable. This method results in $2400 \mathrm{MWh}_{\mathrm{th}} /$ tonne waste and $220 \mathrm{MWh}_{\mathrm{e}} /$ tonne waste. Table 9 summarizes the break-up of the energy and greenhouse gas intensities for SvL\&S per $\mathrm{kWh}_{\mathrm{e}}$ of electricity produced. Furthermore, $200 \%$ of the construction energy is taken into account for decommissioning, based on rough estimates. Of this $200 \%, 50 \%$ pts is estimated for the maintenance of the nuclear power plant after shutdown. This contribution can be seen as a 'temporary storage' of the reactor building and is therefore included here. The estimation is based on an annual energetic expenditure of $0.5 \%$ of the construction energy over a waiting period of 100 years before the decommissioning starts. Table 9 shows that this contribution overshadows the temporary storage of the fuel elements. Since the construction energy calculated by SvL\&S is very high when compared to other studies in the open literature, relating other process steps to the energy intensity associated with the construction of the power plant results in a large energy and GHG intensity for these process steps as well.

\subsection{Final disposal}

After the temporary storage, the waste produced in the different process steps is disposed of. LLW and ILW are currently disposed of in near surface facilities, whereas HLW is proposed to be disposed of in deep geological strata, e.g. clay or granite formations. This 
process step is amongst the most difficult to analyze since data are lacking on the energy expenditure of this process stage.

This process step was not considered by Voorspools et al. (2000), since they only considers the construction, operation and decommissioning of the power plant itself. For the other studies, the results were split up in a way similar to the temporary storage of the waste.

Lenzen et al. (2006) use material inputs from the Environmental Product Declaration to perform a simplified PCA for Torness scenario (UKNL, 2005) concerning the disposal of LLW, ILW and HLW. The thermal energy use associated with the fabrication of these materials is based on energetic intensities from different studies. Hereby, the highest intensities are used as a conservative approach. For the electricity, an estimation of a continual input of 3 MW is assumed over 40 years. Careful analyzing UKNL (2005) does not clarify where this $3 \mathrm{MW}$ comes from. So the thermal energy in this study reflects the construction energy needs, whereas the electrical input comes down to the operational energy. The figures obtained are $119 \mathrm{MWh}_{\mathrm{th}} /$ tonne waste and $329 \mathrm{MWh}_{\mathrm{e}} /$ tonne waste for $\mathrm{HLW}$, 1.09 $\mathrm{MWh}_{\mathrm{th}} /$ tonne waste and 24.4 $\mathrm{MWh}_{\mathrm{e}} /$ tonne waste for both ILW and LLW. The estimated electrical input, accounting for the operational energy, strongly overshadows the construction energy. Table 10 shows the break-up for the different process stages. For the depleted uranium, a reconversion from $\mathrm{UF}_{6}$ to metallic uranium is considered, requiring an energy input of $447 \mathrm{MWh}_{\mathrm{th}} /$ tonne waste and $24.9 \mathrm{MWh}_{\mathrm{e}} /$ tonne waste, according to data provided by SvL\&S. This reconversion overshadows the other contributions, because of the large amounts of both depleted uranium and energy involved.

Storm van Leeuwen and Smith (2005) take into account conditioning, temporary storage and disposal of the waste. The energy input for the conditioning of the different types of waste is assumed to be equal to the construction energy of the power plant per unit mass. This consideration may not reflect reality since there is no energetic nor physical link between conditioning containers and building a nuclear power plant. For the final disposal of the fuel elements and the operational waste, SvL\&S make use of respectively four times and three times the energy intensity of the mining per unit of mass. The operational waste under 
consideration is produced in different process steps: conversion, fuel element production and the operation of the nuclear reactor. The amounts of waste produced per $\mathrm{GWy}_{\mathrm{e}}$ are obtained from studies by the International Atomic Energy Agency (IAEA, 1988, 1995; Orita, 1995). A reconversion, conditioning and final disposal is considered for the depleted uranium. The reconversion is assumed to take the same amount of energy per unit mass as the conversion. Furthermore, the energy intensities for conditioning and disposal of the depleted uranium are the same as for the operational waste. SvL\&S do not take into account the waste produced with the decommissioning stage. According to the authors, the energy use related to the disposal of this waste is included with the estimated $200 \%$ of the construction energy for the decommissioning stage.

Although the amounts of waste used by SvL\&S result from literature values, the energy expenditures do not reflect real conditions, since they are related the construction energy and the mining of the ore.

\subsection{Decommissioning of the power plant}

At the end of the lifetime the nuclear power plant is dismantled. Due to contamination, the different structure materials can possibly be activated and need proper treatment. Different scenarios are possible, using different waiting times in order to let the radioactive elements decay. Because of lack of data available in the literature, the different studies use estimations in order to calculate the related energy use and GHG emissions related the decommissioning stage.

Voorspools et al. (2000) make use of a waiting period of 60 to 70 during which a large fraction of the radioactivity will decay. Thereafter, a large fraction of the demolishment of the power plant (90\% of steel, $96 \%$ of concrete and $65 \%$ of other materials) can be performed using classical techniques involving a small energy use (respectively $10 \%$ of the fabrication energy for concrete and $2 \%$ for steel and other materials). For the contaminated parts, a distinction is made between materials that can be recycled and reused in nuclear applications and material that has to be disposed of. An estimation of $50 \%$ of the fabrication 
energy is used as an estimate for the recyclable fraction. The non recyclable fraction is stored in special disposal repositories. Hereby, Voorspools et al. (2000) estimate the energy use related to the demolishment of this fraction and the construction of the temporary storage facilities at about $30 \%$ of the total fabrication energy of these materials. The resulting figures, mainly based on engineering judgements, are very low when compared to the other studies.

Lenzen et al. (2006) make use of data from World Nuclear Association (WNA, 2006) which states energy inputs of $4.3 \mathrm{PJ}$ to $6.2 \mathrm{PJ}$ for the decommissioning stage. This energy expenditures results in $35 \%$ of the energy associated with the construction of the power plant.

Storm van Leeuwen and Smith (2005) make a distinction between an environmental responsible option in which the power plant is dismantled after a waiting period of 100 years and an option 'après nous la deluge' in which the dismantling of the power plant is left to the future generations. In the environmental responsible option, a waiting period of 100 years is presumed with an associated expenditure of $50 \%$ of the construction energy. This fraction is considered as a fraction of the temporary storage of the waste (see 3.8). Another $50 \%$ of the construction energy is estimated to clean the cooling circuit and an additional $100 \%$ is reserved for the dismantling of the reactor. According to the authors, these estimates also include the final disposal of the waste resulting from the decommissioning stage, which are not accounted for separately "because of the large uncertainties in all of the dismantling costs”, as stated by the SvL\&S. This stage results in a large fraction in the overall energy (Table 4) and greenhouse gas emissions (Table 3) since all expenditures are related to the construction energy.

\section{Influence of the fuel mix}

The greenhouse gas emissions related to the overall nuclear fuel cycle depend to a large extent on the assumptions made on the energy carriers used for the thermal and electrical energy generation. Both Torfs et al. (1998) and Voorspools et al. (2000) make a distinction 
between different types of fossil energy sources used in the fuel cycle. A range of $6.9-17.6$ $\mathrm{g} \mathrm{CO}_{2} / \mathrm{kWh}_{\mathrm{e}}$ is applicable for the combination of the former studies by changing the electricity mix for the diffusion plant from an all nuclear feed to a European (former UCTPE, GHG coefficient from the ETH database (Frishknecht et al., 1995)) electricity mix and considering a PCA and IOA as lower and upper limit for the construction stage.

Lenzen et al. (2006) make use of a very conservative assumption on the energy and greenhouse gas coefficients by stating coal as the energy carrier used for both thermal and electrical energy generation. Storm van Leeuwen and Smith (2005) make use of a nuclear electricity input for the electricity used in the different process steps and burning oil as a primary energy carrier for thermal energy. In order to compare the results for the different studies, a variation in the fuel mix was considered for both Lenzen et al. (2006) and Storm van Leeuwen and Smith (2005). Table 12 summarizes the variations for the greenhouse gas emissions. The overall greenhouse gas intensities from Table 3 are printed in italic.

Lenzen et al. (2006) mention a range of $10-130 \mathrm{~g} \mathrm{CO}_{2} / \mathrm{kWh}_{\mathrm{e}}$, resulting from a sensitivity analysis of the main parameters (power plant efficiency, greenhouse gas intensities, chain losses, lifetime, capacity factor, ore grade, etc.) When the greenhouse gas intensities used in this study are changed in line with established studies, the related greenhouse gas emissions are significantly lowered compared to the baseline scenario. For Storm van Leeuwen and Smith (2005), altering the assumptions on the fuel mix results in higher values for the overall emissions. The baseline study makes use of a nuclear electricity input. In their break even charts, SvL\&S do not relate greenhouse gas emissions to this electricity. When another energy carrier for thermal energy and another electricity mix is presumed, the resulting greenhouse gas emissions are higher due the fraction of emissions which stems from the electricity use in the overall chain.

Although the different studies put a high emphasis on greenhouse gas emissions, these emissions are primarily calculated as a byproduct of an energetic analysis. Therefore, in calculating the greenhouse gas emissions related to nuclear electricity generation, a proper distinction has to be made between the different energy carriers used in the life cycle. The 
overall emissions show a large dependency on the assumptions of thermal and electrical GHG coefficients, reflected by the background economy. Averaging GHG emissions from different studies, as performed by Sovacool (2008) (resulting in a mean value of $66 \mathrm{~g}$ $\mathrm{CO}_{2} / \mathrm{kWh}_{\mathrm{e}}$ ) is an improper manner to deal with life cycle studies because it does not take into account these differences.

\section{Conclusion}

Within this comparative study, three life cycles were recalculated in order to make a comparison of both energy use and greenhouse gas emissions for the different process steps in the nuclear fuel cycle. Regarding the energy use, the divergent results are due to the assessment method, the input data but also due to estimates and assumptions. These varying energy intensities are in their turn reflected in the diverging GHG emissions. As discussed in this paper, the GHG intensity of the background economy forms a major influencing parameter as well.

Torfs et al. (1998) and Voorspools et al. (2000) obtain the lowest greenhouse gas emissions (7.7 $\mathrm{g} \mathrm{CO}_{2} / \mathrm{kWh}_{\mathrm{e}}$, with a range of $\left.6.9-17.6 \mathrm{CO}_{2} / \mathrm{kWh}_{\mathrm{e}}\right)$. The energy inputs for the upstream process stages, resulting from the ETH-database (Frishknecht et al., 1995), are low compared to the ones used in the other studies. The low energy intensity is partly caused by the assessment method used in the upstream part of the life cycle (PCA), and the limited scope of this study. When a European electricity mix is used for the gas diffusion stage and an IOA is used for the construction stage, an overall result of $17.6 \mathrm{~g} \mathrm{CO}_{2} / \mathrm{kWh}_{\mathrm{e}}$ is obtained. In the three studies under consideration, only Torfs et al. (1998) and Voorspools et al. (2000) do make a proper distinction and make use of different thermal energy carriers. However, these results do not include temporary storage and final disposal of the waste. For the decommissioning of the power plant, the assumptions used result in a very low greenhouse gas contribution $\left(0.11 \mathrm{~g} \mathrm{CO}_{2} / \mathrm{kWh}_{\mathrm{e}}\right)$.

The greenhouse gas emissions obtained by Lenzen et al. (2006) are higher (57.7 g $\mathrm{CO}_{2} / \mathrm{kWh}_{\mathrm{e}}$ ) than those calculated by the former study. This difference results from higher 
energetic inputs, partly due to the IOA used for a number of process steps, combined with coal used for the generation of both thermal and electrical energy. Relatively large fractions results from the operation and maintenance of the power plant $(25 \%)$ on the one hand and from the enrichment $(28 \%)$ on the other hand. The overall emissions are derived from the thermal and electrical energy inputs by multiplying them with overall greenhouse gas emissions coefficients. With assumptions on energy carriers that do more reflect a European context, the emissions are lowered significantly, resulting in $32 \mathrm{~g} \mathrm{CO}_{2} / \mathrm{kWh}_{\mathrm{e}}$ for a European electricity mix and natural gas for thermal energy.

Storm van Leeuwen and Smith (2005) obtain the largest emissions. When considering current day ore grades, a large fraction from the overall emissions $\left(117 \mathrm{~g} \mathrm{CO}_{2} / \mathrm{kWh}_{\mathrm{e}}\right)$ stems from the construction, operation and decommissioning of the power plant and the waste treatment. These high values result from the assessment method for the construction energy in which total monetary costs are multiplied with average energy intensity. The same method is used for other process steps as well. The intensities associated with the decommissioning stage are amongst the highest values in the literature.

When very low ore grades are considered, a large fraction of the overall emissions (337 $\mathrm{g}$ $\mathrm{CO}_{2} / \mathrm{kWh}_{\mathrm{e}}$ ) results from the mining, milling and cleanup of the mine site for which the intensities are calculated based on a hypothetical model which is not found in current day practice. The high energy intensity in the mining and milling stage is partly caused by the high energetic intensities and by the regression formula that is used for extraction yield. Using this formula for low ore grades comes down to an interpolation of hypothetic data. Storm van Leeuwen and Smith make use of a nuclear electricity input and burning oil for thermal energy. Assuming a European electricity mix results in even higher emissions.

These indirect greenhouse emissions have to be compared to the direct emissions resulting from other energy conversion technologies: With the best available power plant efficiencies, emissions for a Combined Cycle Gas Turbine (CCGT) can be as low as $350 \mathrm{~g}$ $\mathrm{CO}_{2} / \mathrm{kWh}_{\mathrm{e}}$, whereas for coal-fired power plants based on sub-critical technology the emissions amount $830 \mathrm{~g} \mathrm{CO}_{2} / \mathrm{kWh}_{\mathrm{e}}$ (IEA, 2008). Even if Carbon Capture and Storage (CCS) 
will be able to reduce these emissions down to $5-10 \%$, these would still be in a range of 20 $-80 \mathrm{~g} \mathrm{CO}_{2} / \mathrm{kWh}_{\mathrm{e}}$ for fossil fuel power plants.

Based on this comparative review, some general remarks can be made. First of all, none of the studies takes into account the different mining techniques (especially in-situ leaching) in a proper manner, either by treating different techniques as being energetically equivalent to other techniques, e.g. Torfs et al. (1998), or by adopting input data from other studies which do not necessarily reflect the current context, e.g. Storm van Leeuwen \& Smith (2005). Secondly, more effort is needed to address the energy and GHG emissions involved with the waste processing, storage and disposal on one hand and the decommissioning of the plant on the other hand, as most of the intensities calculated in the three studies are based on widely varying estimations.

Recently, high emphasis is put on the indirect greenhouse gas emissions associated with the nuclear fuel cycle. However, the overall emission coefficients largely depend on the assumptions of the different primary energy carriers used. A distinction between the different energy carriers used for thermal and electrical energy generation results in a detailed calculation of the resulting emissions. When data are lacking to make this distinction properly, studies should include results for other energy mixes as well. 


\section{References}

[ACA] Australian Coal Association, 2001. Electricity from a nuclear power station, Case study B16. ACA, Canberra, Australia.

Blok, K., Hendriks, C.A., 1989. Elektriciteitsproduktietechnieken voor de komende twintig jaar. Vergelijking van Milieu-effecten. Report W-90006, Department of Science, Technology and Society, University of Utrecht, Netherlands.

Bullard, C.W., Penner, P.S., Pilati, D.A., 1978. Net energy analysis, Handbook for combining process and input/output analysis. Resources and Energy, vol. 1, 1978: 267-313.

Burkhardt, J., Feck, N., Große Böckmann, Th., Koch, M.K., Kruse, Ph., Wagner, H.-J., 2007. $\mathrm{CO}_{2}$-Emissionen der Kernenergie - Vergleich mit anderen Stromerzeugungstechniken. Fachseitschrift atw. 52: 488 - 495.

Chapman, P.F., 1975. Energy analysis of nuclear power stations. Energy Policy 3(4): 285-298.

[ERDA] Energy Research and Development Agency, 1976. Net Energy Analysis of Nuclear Power Production. A national plan for energy research, development and demonstration: creating energy choices for the future, ERDA 76/1, Washington DC.

Frischknecht, R., Hoftstetter, P., Knoepfel, I., 1995. Ökoinventare von Energiesystemen, Eidgenössige Technische Hochschule, Zürich.

Fthenakis, V.M., Kim, H.C., 2007. Greenhouse-gas emissions from solar electric- and nuclear power: A life-cycle study. Energy Policy 35: 2549-2557.

Heinloth, K, 1997. Die Energiefrage. Vieweg, Braunschweig, Germany.

Hewlett, J.G., 1992. The operating costs and longevity of nuclear power plants. Energy Policy 20(7): 608-622.

[IAEA] International Atomic Energy Agency, 1988. Factors relevant to the recycling or reuse of components arising from the decommissioning and refurbishment of nuclear facilities. Technical Report Series No. 293. IAEA, Vienna, Austria. 
[IAEA] International Atomic Energy Agency, 1995. Minimalisation of radioactive waste from nuclear power plants and the back end of the nuclear fuel cycle. Technical Report Series No. 377. IAEA, Vienna, Austria.

[IEA] International Energy Agency, 2005. Energy Policies of IEA Countries; Australia 2005 Review. IEA, Paris, France.

[IEA] International Energy Agency, 2008. Energy Technology Perspectives 2008: Scenarios and Strategies to 2050. OECD, Paris, France.

Kistemaker J., 1975. Energie-analyse van de totale kernenergiecyclus gebaseerd op lichtwater reactoren. Foundation for Fundamental Research on Matter, Netherlands.

Kistemaker J., 1976. Aanvulling op: Energie-analyse van de totale kernenergiecyclus gebaseerd op licht-water reactoren. Foundation for Fundamental Research on Matter, Netherlands.

Lenzen, M., Dey, C., Hardy, C., Bilek, M., 2006. Life-cycle energy balance and greenhouse gas emissions of nuclear energy in Australia. Report to the prime minister's uranium mining, processing and nuclear energy review (UMPNER), Internet site http://www.isa.org.usyd.edu.au/publications/documents/ISA Nuclear_Report.pdf, Sydney, Australia, ISA, University of Sydney.

Lenzen, M., 2008. Life cycle and greenhouse gas emissions of nuclear energy: A review. Energy Conversion \& Management 49: 2178-2199.

Orita, Y., 1995. Preliminary assessment on nuclear fuel cycle and energy consumption, Part of: Assessment of greenhouse gas emissions from the full energy chain for nuclear power and other sources. Working material. IAEA, Vienna, 26-28 September 1995.

Roberts, P.C., 1982. Energy and value. Energy Policy 10(3): 171-180.

Rotty, R.M., Perry, A.M., Reister, D.B., 1975. Net energy from nuclear power. IEA Report IEA-75-3. Oak Ridge, TN, USA: Institute for Energy Analysis, Oak Ridge Associated Universities. 
Sovacool, B.K., 2008. Valuing the greenhouse gas emissions from nuclear power: A critical survey. Energy Policy 36: 2950-2963.

Storm van Leeuwen, J.W., Smith P., 2005. Nuclear power - the energy balance. (Netherlands), available at <http://www.stormsmith.nl $>$.

Torfs, R., Huybrechts, D., Wouters, G., 1998. Broeikasgasemissies, verzurende emissies en energiegebruik van energiedragers vanaf de ontginning tot aan de eindgebruiker, Flemish Institute for Technological Researc (VITO).

[UKNL] United Kingdom Nirex Limited, 2005. Nirex inputs to Environmental Product Declaration for Torness power station, Technical Note 484461. United Kingdom Nirex Limited, Harwell, UK.

Voorspools, K.R., Brouwers, E.A., D'haeseleer, W.D., 2000. Energy content and indirect greenhouse gas emissions in 'emission-free' power plants: results for the Low Countries. Applied Energy 67: 307-330

[WEC] World Energy Council, 2007. Survey of Energy Resources 2007. WEC, London.

[WNA] World Nuclear Association, 2006. Energy analysis of power systems, Information Paper 11. WNA, London, available at < http://www.worldnuclear.org/info/inf11.htm> 


\section{Appendix: Results from Torfs et al. (1998)}

Within this appendix, the results from Torfs et al. (1998) for the nuclear fuel cycle are summarized since the original study is written in Dutch. Table 13 summaries the energy use and greenhouse gas emissions per mg of enriched uranium $(3.8 \% \mathrm{U}-235)$ entering the reactor. These results were converted to ' $\mathrm{kWh}_{\mathrm{e}}$ ', using a burn up of $45 \mathrm{MWd} / \mathrm{kg} \mathrm{U}$ and a nuclear power plant efficiency of 33\%. A European electricity mix is used except for the fraction of the fuel enriched by gas diffusion technology, for which an all nuclear input was considered. For the enrichment phase, the base case considers $50 \%$ of the fuel to be enriched using the energy intensive gas diffusion (Eurodif facilities in France, Tricastin) and 50\% with ultracentrifuge technology (Urenco facilities in the Netherlands, Germany, UK). Torfs et al. (1998) also calculate the emissions and energy use when a European electricity mix is used for the gas diffusion, resulting in $4.50 \mathrm{~g} \mathrm{CO}_{2}$-eq./mg $\mathrm{U}$ for the upstream part of the life cycle, with $3.81 \mathrm{~g} \mathrm{CO}_{2}$-eq./mg U due to the enrichment phase. Furthermore, a large fraction from the emissions for the enrichment stage results from the emissions of CFC's.

A further distinction is made between different primary energy carriers in order to calculate the greenhouse gas emissions related to the fossil fuel used in the different process stages. 'Precombustion energy' is the primary energy associated with the fabrication of the energy carriers used within that process step. It is a second order term taking into account the indirect energy associated with the use of a certain energy carrier in every step of the fuel cycle. The largest contribution in the precombustion energy results from the enrichment due to the large amount of electricity used for the fraction produced by the energy intensive diffusion technology. 
Table 1

Scope of the studies and assessment method

\begin{tabular}{llll}
\hline & $\begin{array}{l}\text { Torfs et al. (1998), } \\
\text { Voorspools et al. } \\
(2000)\end{array}$ & $\begin{array}{l}\text { Storm van Leeuwen } \\
\text { and Smith (2005) }\end{array}$ & Lenzen et al. (2006) \\
\hline Mining & PCA & H-IOA & H-IOA (C) \\
Milling & PCA & C & H-IOA (C) \\
Clean up of mine & - & $\begin{array}{l}\text { Estimations based } \\
\text { on mining }\end{array}$ & - \\
Conversion & PCA & H-IOA & H-IOA \\
Enrichment & PCA & C & C \\
Fuel fabrication & PCA & H-IOA & H-IOA \\
Transport & PCA & - & H-IOA \\
Construction & PCA and IOA & AEI & IOA \\
$\begin{array}{l}\text { Operation, Maintenance and } \\
\text { Refurbishment }\end{array}$ & H-IOA & AEI & Simplified IOA \\
Temporary storage & - & AEI & Simplified PCA \\
Final disposal & - & AEI & Simplified PCA \\
Decommissioning & PCA & AEI & C \\
\hline
\end{tabular}

AEI: Average Energy Intensity; C: Input data resulting from a combination of different studies; H-IOA: Hybrid Input-Output Analysis; IOA: Input-Output Analysis, PCA: Process Chain Analysis 
Table 2

Parameters for the different studies

\begin{tabular}{|c|c|c|c|c|}
\hline Reference $\rightarrow$ & & $\begin{array}{l}\text { Torfs et al. } \\
(1998), \\
\text { Voorspools et al. } \\
(2000)\end{array}$ & $\begin{array}{l}\text { Storm van } \\
\text { Leeuwen and } \\
\text { Smith (2005) }\end{array}$ & $\begin{array}{l}\text { Lenzen et } \\
\text { al. (2006) }\end{array}$ \\
\hline Ore grade & {$\left[\% U_{3} O_{8}\right]$} & 0.2 & $\begin{array}{l}0.15 \\
0.01\end{array}$ & 0.15 \\
\hline Burn up of the fuel & {$[M W d / \mathrm{kg} U]$} & 45 & 46 & 45 \\
\hline Fraction U-235 in the feed $x_{f}$ & {$\left[\% \mathrm{~m}^{235} \mathrm{U} / \mathrm{m} U\right]$} & 0.71 & 0.72 & 0.71 \\
\hline Fraction U-235 in the product $x_{p}$ & {$\left[\% \mathrm{~m}^{235} \mathrm{U} / \mathrm{m} U\right]$} & 3.8 & 3.5 & $\begin{array}{l}3.3 \\
4.2^{+}\end{array}$ \\
\hline Fraction U-235 in the depleted tails $x_{t}$ & {$\left[\% m^{235} U / m U\right]$} & 0.28 & 0.25 & 0.20 \\
\hline Separative Work Unit (SWU) & $\begin{array}{l}{[k g S W U / k g} \\
\left.U_{\text {enriched }}\right]\end{array}$ & 5.101 & 4.756 & $\begin{array}{l}4.97 \\
7.01^{+}\end{array}$ \\
\hline Efficiency nuclear power plant & {$[\%]$} & 33 & 32 & 30 \\
\hline Capacity factor & {$[\%]$} & 85.4 & 82 & 85 \\
\hline Lifetime & [year] & 40 & 29 & 35 \\
\hline $\begin{array}{l}\text { Conversion electrical to primary } \\
\text { energy }\end{array}$ & {$[-]$} & 2.638 & $2.638^{*}$ & 3.1 \\
\hline GHG-intensity electrical energy & {$\left[\mathrm{g} \mathrm{CO} \mathrm{C}_{2}-e q . / \mathrm{kWh}\right]$} & 437 & 0 & 1000 \\
\hline GHG-intensity thermal energy & {$\left[\mathrm{g} \mathrm{CO}_{2}-e q . / \mathrm{kWh}\right]$} & $-^{* *}$ & 270 & 324 \\
\hline
\end{tabular}

${ }^{+}$: A distinction is made between the first reactor load (enriched to 3.3\%) load and the reloading (enriched to $4.2 \%)$

*: In the energy break-even charts Storm van Leeuwen and Smith (2005) add thermal and electrical energy without a conversion factor. In our comparative study, the conversion factor from Torfs et al. (1998) is used ${ }^{* * *}:$ No single factor is defined, see text 
Table 3

Breakup of the greenhouse gas intensities for the three studies

\begin{tabular}{|c|c|c|c|c|}
\hline GHG emissions & $\begin{array}{l}\text { Torfs et al. } \\
\text { (1998), } \\
\text { Voorspools et al. } \\
(2000)\end{array}$ & $\begin{array}{l}\text { Storm van } \\
\text { Leeuwen and } \\
\text { Smith (2005) }\end{array}$ & $\begin{array}{l}\text { Storm van } \\
\text { Leeuwen and } \\
\text { Smith (2005) }\end{array}$ & $\begin{array}{l}\text { Lenzen et al. } \\
(2006)\end{array}$ \\
\hline$\left[\mathrm{g} \mathrm{CO}_{2}\right.$-eq./kWh $]$ & & Soft ore $-0.15 \%$ & Hard ore $-0.01 \%$ & \\
\hline Mining \& Milling & 0.83 & 3.14 & 105.69 & 3.77 \\
\hline Clean up of mine & - & 6.11 & 123.77 & - \\
\hline Conversion & 1.05 & 2.57 & 2.57 & 3.92 \\
\hline Enrichment & 1.77 & 2.94 & 2.94 & 16.10 \\
\hline Fuel fabrication & 0.05 & 0.63 & 0.63 & 1.82 \\
\hline Transport & 0.022 & - & - & 0.034 \\
\hline Construction & 2.12 & 23.78 & 23.78 & 5.38 \\
\hline $\begin{array}{l}\text { Operation, Maintenance and } \\
\text { Refurbishment }\end{array}$ & 0.80 & 19.04 & 19.04 & 13.78 \\
\hline Temporary storage & - & 13.75 & 13.75 & 4.01 \\
\hline Final disposal & - & 9.59 & 9.59 & 6.99 \\
\hline Decommissioning & 0.11 & 35.67 & 35.67 & 1.88 \\
\hline TOTAL & $7.72^{\mathrm{a}}$ & 117.22 & 337.42 & 57.69 \\
\hline
\end{tabular}

${ }^{\mathrm{a}}$ : Including $0.97 \mathrm{~g} \mathrm{CO}_{2}$-eq./ $/ \mathrm{kWh}_{\mathrm{e}}$ for indirect $\mathrm{GHG}$ emissions (related to auxiliary raw materials and infrastructure in the upstream part of the cycle) based on literature data 
Table 4

Break up of the energy use in the nuclear life cycle

\begin{tabular}{|c|c|c|c|c|c|c|c|c|c|c|c|c|}
\hline & \multicolumn{4}{|c|}{ Thermal energy $\left[k W h_{t h} / k W h_{e}\right]$} & \multicolumn{4}{|c|}{ Electrical energy $\left[k W h_{e} / k W h_{e}\right]$} & \multicolumn{4}{|c|}{ Total primary energy $\left[k W h_{p} / k W h_{e}\right]$} \\
\hline & $\begin{array}{l}\text { Torfs et al. } \\
(1998), \\
\text { Voorspools } \\
\text { et al. (2000) }\end{array}$ & $\begin{array}{l}\text { Storm van } \\
\text { Leeuwen } \\
\text { and Smith } \\
(2005) \\
\text { Soft ore - } \\
0.15 \%\end{array}$ & $\begin{array}{l}\text { Storm van } \\
\text { Leeuwen } \\
\text { and Smith } \\
(2005) \\
\text { Hard ore - } \\
0.01 \%\end{array}$ & $\begin{array}{l}\text { Lenzen et } \\
\text { al. (2006) }\end{array}$ & $\begin{array}{l}\text { Torfs et al. } \\
(1998), \\
\text { Voorspools et } \\
\text { al. }(2000)\end{array}$ & $\begin{array}{l}\text { Storm van } \\
\text { Leeuwen } \\
\text { and Smith } \\
(2005) \\
\text { Soft ore - } \\
0.15 \%\end{array}$ & $\begin{array}{l}\text { Storm van } \\
\text { Leeuwen } \\
\text { and Smith } \\
(2005) \\
\text { Hard ore - } \\
0.01 \%\end{array}$ & $\begin{array}{l}\text { Lenzen et } \\
\text { al. (2006) }\end{array}$ & $\begin{array}{l}\text { Torfs et al. } \\
\text { (1998), } \\
\text { Voorspools } \\
\text { et al. (2000) }\end{array}$ & $\begin{array}{l}\text { Storm van } \\
\text { Leeuwen } \\
\text { and Smith } \\
(2005) \\
\text { Soft ore - } \\
0.15 \%\end{array}$ & $\begin{array}{l}\text { Storm van } \\
\text { Leeuwen } \\
\text { and Smith } \\
(2005) \\
\text { Hard ore - } \\
0.01 \%\end{array}$ & $\begin{array}{l}\text { Lenzen et } \\
\text { al. (2006) }\end{array}$ \\
\hline Mining and miling & $3.80 \mathrm{E}-03$ & $1.16 \mathrm{E}-02$ & 3.91E-01 & $6.74 \mathrm{E}-03$ & $0.00 \mathrm{E}+00$ & $1.57 \mathrm{E}-03$ & $2.45 \mathrm{E}-01$ & $1.58 \mathrm{E}-03$ & $3.81 \mathrm{E}-03$ & $1.58 \mathrm{E}-02$ & $1.05 \mathrm{E}+00$ & $1.16 \mathrm{E}-02$ \\
\hline Clean up of mine & - & $2.26 \mathrm{E}-02$ & $4.58 \mathrm{E}-01$ & - & - & 2.83E-03 & $5.73 \mathrm{E}-02$ & - & - & $3.02 \mathrm{E}-02$ & $6.12 \mathrm{E}-01$ & - \\
\hline Conversion & $5.25 \mathrm{E}-03$ & $9.52 \mathrm{E}-03$ & $9.52 \mathrm{E}-03$ & $1.09 \mathrm{E}-02$ & $2.42 \mathrm{E}-04$ & $3.51 \mathrm{E}-04$ & $3.51 \mathrm{E}-04$ & $4.01 \mathrm{E}-04$ & 5.89E-03 & $1.05 \mathrm{E}-02$ & $1.05 \mathrm{E}-02$ & $1.21 \mathrm{E}-02$ \\
\hline Enrichment & $1.52 \mathrm{E}-03$ & $1.09 \mathrm{E}-02$ & $1.09 \mathrm{E}-02$ & $4.03 \mathrm{E}-03$ & $1.82 \mathrm{E}-02$ & $2.15 \mathrm{E}-02$ & 2.15E-02 & $1.48 \mathrm{E}-02$ & 5.99E-02 & $6.86 \mathrm{E}-02$ & $6.86 \mathrm{E}-02$ & 4.97E-02 \\
\hline Fuel fabrication & $8.61 \mathrm{E}-05$ & $2.34 \mathrm{E}-03$ & $2.34 \mathrm{E}-03$ & $2.52 \mathrm{E}-03$ & $6.37 \mathrm{E}-05$ & $9.37 \mathrm{E}-04$ & $9.37 \mathrm{E}-04$ & $1.01 \mathrm{E}-03$ & $2.57 \mathrm{E}-04$ & $4.86 \mathrm{E}-03$ & $4.86 \mathrm{E}-03$ & $5.63 \mathrm{E}-03$ \\
\hline Transport & 7.83E-05 & - & - & $1.04 \mathrm{E}-04$ & $0.00 \mathrm{E}+00$ & - & - & $0.00 \mathrm{E}+00$ & $7.87 \mathrm{E}-05$ & - & - & $1.04 \mathrm{E}-04$ \\
\hline Construction & n.a. & 8.81E-02 & $8.81 \mathrm{E}-02$ & $1.49 \mathrm{E}-02$ & n.a. & $1.83 \mathrm{E}-02$ & $1.83 \mathrm{E}-02$ & $5.53 \mathrm{E}-04$ & $8.76 \mathrm{E}-03$ & $1.37 \mathrm{E}-01$ & $1.37 \mathrm{E}-01$ & $1.66 \mathrm{E}-02$ \\
\hline $\begin{array}{l}\text { Operation. } \\
\text { Maintenance and } \\
\text { Refurbishment }\end{array}$ & n.a. & $7.05 \mathrm{E}-02$ & $7.05 \mathrm{E}-02$ & $3.82 \mathrm{E}-02$ & n.a. & $6.65 \mathrm{E}-03$ & $6.65 \mathrm{E}-03$ & $1.41 \mathrm{E}-03$ & $3.61 \mathrm{E}-03$ & 8.84E-02 & $8.84 \mathrm{E}-02$ & $4.25 \mathrm{E}-02$ \\
\hline Temporary storage & - & 5.09E-02 & $5.09 \mathrm{E}-02$ & $8.77 \mathrm{E}-03$ & - & $1.05 \mathrm{E}-02$ & $1.05 \mathrm{E}-02$ & $1.17 \mathrm{E}-03$ & - & 7.92E-02 & $7.92 \mathrm{E}-02$ & $1.24 \mathrm{E}-02$ \\
\hline Final disposal & - & $3.55 \mathrm{E}-02$ & $3.55 \mathrm{E}-02$ & $1.35 \mathrm{E}-02$ & - & $5.07 \mathrm{E}-03$ & $5.07 \mathrm{E}-03$ & $2.63 \mathrm{E}-03$ & - & 4.91E-02 & 4.91E-02 & $2.16 \mathrm{E}-02$ \\
\hline Decommissioning & n.a. & 1.32E-01 & $1.32 \mathrm{E}-01$ & $5.22 \mathrm{E}-03$ & n.a. & $2.75 \mathrm{E}-02$ & $2.75 \mathrm{E}-02$ & $1.94 \mathrm{E}-04$ & 4.17E-04 & $2.06 \mathrm{E}-01$ & $2.06 \mathrm{E}-01$ & $5.81 \mathrm{E}-03$ \\
\hline TOTAL & $1.07 \mathrm{E}-02$ & 4.34E-01 & $1.25 \mathrm{E}+00$ & $1.05 \mathrm{E}-01$ & $1.85 \mathrm{E}-02$ & $9.53 \mathrm{E}-02$ & $3.93 \mathrm{E}-01$ & $2.37 \mathrm{E}-02$ & $8.69 \mathrm{E}-02^{\mathrm{a}}$ & $6.90 \mathrm{E}-01$ & $2.30 \mathrm{E}+00$ & $1.78 E-01$ \\
\hline
\end{tabular}

${ }^{\mathrm{a}}$ : Including $4.09 \mathrm{E}-03 \mathrm{~kW}_{\mathrm{th}} / \mathrm{kWh}_{\mathrm{e}}$ for indirect energy use (related to auxiliary raw materials and infrastructure in the upstream part of the cycle) based on literature data n.a.: not available 
Table 5

Energy intensities for the mining and milling of the ore per $\mathrm{kg}$ of ore

\begin{tabular}{|c|c|c|c|c|c|c|}
\hline Reference & $\begin{array}{l}\text { Mining } \\
\text { Thermal } \\
{\left[M J_{t h} / \mathrm{kg} \text { ore }\right]}\end{array}$ & $\begin{array}{l}\text { Electrical } \\
{\left[M J_{e} / k g \text { ore] }\right.}\end{array}$ & $\begin{array}{l}\text { Milling } \\
\text { Thermal } \\
{\left[M J_{t h} / \mathrm{kg} \text { ore }\right]}\end{array}$ & $\begin{array}{l}\text { Electrical } \\
{\left[M J_{e} / \mathrm{kg} \text { ore }\right]}\end{array}$ & $\begin{array}{l}\text { Total } \\
\text { Thermal } \\
{\left[M J_{t h} / \mathrm{kg} \text { ore }\right]}\end{array}$ & $\begin{array}{l}\text { Electrical } \\
{\left[M J_{e} / k g \text { ore] }\right.}\end{array}$ \\
\hline $\begin{array}{l}\text { Torfs et al. (1998), } \\
\text { (mix) }\end{array}$ & 0.264 & 0 & 0.61 & 0 & 0.874 & 0 \\
\hline $\begin{array}{l}\text { Torfs et al. (1998), } \\
\text { UGM }\end{array}$ & 0.512 & 0 & 0.61 & 0 & 1.122 & 0 \\
\hline $\begin{array}{l}\text { Torfs et al. (1998), } \\
\text { OPM }\end{array}$ & 0.113 & 0 & 0.61 & 0 & 0.723 & 0 \\
\hline $\begin{array}{l}\text { Storm van Leeuwen } \\
\text { and Smith (2005), } \\
\text { soft ore }^{1}\end{array}$ & 0.939 & 0.117 & 1.11 & 0.159 & 2.056 & 0.274 \\
\hline $\begin{array}{l}\text { Storm van Leeuwen } \\
\text { and Smith (2005), } \\
\text { hard ore }^{1}\end{array}$ & 0.939 & 0.117 & 0.377 & 4.055 & 3.415 & 2.135 \\
\hline Lenzen et al. (2006) & 0.443 & 0.196 & 0.774 & 0.092 & 1.217 & 0.288 \\
\hline
\end{tabular}

${ }^{1}$ : Data were reconstructed from Storm van Leeuwen and Smith (2005) by calculating the thermal and electrical energy from the total energy and the thermal to electrical energy ratio. In the comparative study results were reconstructed using the energy intensities from the 'Total' column, which are also used by SvL\&S. 
Table 6

Energy-intensities for the enrichment step per kg Separation Work Unit (SWU)

\begin{tabular}{|c|c|c|c|c|c|c|c|}
\hline \multirow[t]{2}{*}{ Reference } & \multicolumn{2}{|c|}{ Gas diffusion (D) } & \multicolumn{2}{|c|}{ Ultracentrifuge (C) } & \multicolumn{3}{|l|}{ Mix } \\
\hline & $\begin{array}{l}\text { Thermal } \\
{\left[k W h_{t h} /\right.} \\
k g S W U]\end{array}$ & $\begin{array}{l}\text { Electrical } \\
{\left[k W h_{e} /\right.} \\
k g S W U] \\
\end{array}$ & $\begin{array}{l}\text { Thermal } \\
{\left[k W h_{t h} /\right.} \\
k g S W U]\end{array}$ & $\begin{array}{l}\text { Electrical } \\
{\left[k W h_{e} /\right.} \\
k g S W U] \\
\end{array}$ & $\begin{array}{l}\text { Share } \\
\text { [\%diffusion- } \\
\text { \%centrifuge] }\end{array}$ & $\begin{array}{l}\text { Thermal } \\
{\left[k W h_{t h} /\right.} \\
k g S W U]\end{array}$ & $\begin{array}{l}\text { Electrical } \\
{\left[k W h_{e} /\right.} \\
k g S W U] \\
\end{array}$ \\
\hline Torfs et al. (1998) & 9.94 & 2400 & 6.78 & 50 & $50 \% \mathrm{D}-50 \% \mathrm{C}$ & 8.36 & 1225 \\
\hline $\begin{array}{l}\text { Storm van Leeuwen } \\
\text { and Smith (2005) }\end{array}$ & 234 & 2821 & 629 & 231 & $30 \% \mathrm{D}-70 \% \mathrm{C}$ & 513 & 1006 \\
\hline Lenzen et al. (2006) & - & - & - & - & $30 \% \mathrm{D}-70 \% \mathrm{C}$ & 253 & 929 \\
\hline
\end{tabular}


Table 7

Energy intensities related to the construction of the power plant

\begin{tabular}{lllll}
\hline Reference & method & Thermal & Electrical & Total primary energy \\
& & {$\left[G W h_{t h} / G W_{e}\right]$} & {$\left[G W h_{e} / G W_{e}\right]$} & {$\left[G W h_{p} / G W_{e}\right]$} \\
\hline Voorspools et al. (2000) & PCA & - & - & 1500 \\
Voorspools et al. (2000) & IOA & - & - & 3972 \\
Storm van Leeuwen and Smith (2005) & national average & 18621 & 3879 & 28854 \\
Lenzen et al. (2006) & energy intensity & 3690 & 137 & 4100 \\
\hline
\end{tabular}


Table 8

Break-up of energy and GHG-intensities for Lenzen et al. (2006) (temporary storage)

\begin{tabular}{|c|c|c|c|c|c|}
\hline \multirow[t]{2}{*}{ Types of waste } & \multirow{2}{*}{$\begin{array}{l}\text { Thermal } \\
{\left[k W h_{t h} / k W h_{e}\right]}\end{array}$} & \multirow{2}{*}{$\begin{array}{l}\text { Electrical } \\
{\left[k W h_{e} / k W h_{e}\right]}\end{array}$} & \multicolumn{2}{|c|}{ Total primary energy } & \multirow{2}{*}{$\begin{array}{l}\mathrm{GHG} \\
{\left[\mathrm{g} \mathrm{CO}_{2} / \mathrm{kWh}_{e}\right]}\end{array}$} \\
\hline & & & {$\left[k W h_{p} / k W h_{e}\right]$} & $\%$ & \\
\hline Fuel elements & $2.25 \mathrm{E}-03$ & $3.00 \mathrm{E}-04$ & $3.18 \mathrm{E}-03$ & 25.69 & 1.03 \\
\hline Structural materials & $2.83 \mathrm{E}-04$ & $3.77 \mathrm{E}-05$ & 3.99E-04 & 3.22 & 0.13 \\
\hline Fuel production & 2.17E-05 & $2.90 \mathrm{E}-06$ & $3.07 \mathrm{E}-05$ & 0.25 & 0.01 \\
\hline Decommissioning & $6.21 \mathrm{E}-03$ & $8.28 \mathrm{E}-04$ & 8.77E-03 & 70.84 & 2.84 \\
\hline Total & 8.77E-03 & 1.17E-03 & 1.24E-02 & - & 4.01 \\
\hline
\end{tabular}


Table 9

Break-up of energy and GHG-intensities for Storm van Leeuwen and Smith (2005) (temporary storage)

\begin{tabular}{llllll}
\hline Types of waste & Thermal & Electrical & \multicolumn{2}{l}{ Total primary energy } & \multicolumn{2}{c}{ GHG } \\
& {$\left[k W h_{t h} / k W h_{e}\right]$} & {$\left[k W h_{e} / k W h_{e}\right]$} & {$\left[k W h_{p} / k W h_{e}\right]$} & $\%$ & {$\left[g \mathrm{CO}_{2} / k W h_{e}\right]$} \\
\hline $\begin{array}{l}\text { Fuel elements } \\
\begin{array}{l}\text { Maintenance after shut- } \\
\text { down }\end{array}\end{array}$ & $6.87 \mathrm{E}-03$ & $1.37 \mathrm{E}-03$ & $1.06 \mathrm{E}-02$ & 13.32 & 1.85 \\
Total & $4.40 \mathrm{E}-02$ & $9.17 \mathrm{E}-03$ & $6.87 \mathrm{E}-02$ & 86.68 & 11.89 \\
\hline
\end{tabular}


Table 10

Break-up of energy and GHG-intensities for Lenzen et al. (2006) (final disposal)

\begin{tabular}{llllll}
\hline Types of waste & Thermal & Electrical & \multicolumn{2}{l}{ Total primary energy } & \multicolumn{2}{l}{ GHG } \\
& {$\left[k W h_{t h} / k W h_{e}\right]$} & {$\left[k W h_{e} / k W h_{e}\right]$} & {$\left[k W h_{p} / k W h_{e}\right]$} & $\%$ & {$\left[g \mathrm{CO}_{2} / k W h_{e}\right]$} \\
\hline Fuel elements & $4.47 \mathrm{E}-04$ & $1.24 \mathrm{E}-03$ & $4.26 \mathrm{E}-03$ & $19.73 \%$ & 1.38 \\
Structural materials & $5.61 \mathrm{E}-05$ & $1.55 \mathrm{E}-04$ & $5.34 \mathrm{E}-04$ & $2.48 \%$ & 0.17 \\
Fuel production & $4.31 \mathrm{E}-06$ & $1.19 \mathrm{E}-05$ & $4.11 \mathrm{E}-05$ & $0.19 \%$ & 0.01 \\
Decommissioning & $2.26 \mathrm{E}-05$ & $5.05 \mathrm{E}-04$ & $1.58 \mathrm{E}-03$ & $7.33 \%$ & 0.51 \\
Depleted uranium & $1.29 \mathrm{E}-02$ & $7.21 \mathrm{E}-04$ & $1.52 \mathrm{E}-02$ & $70.28 \%$ & 4.92 \\
Total & $\mathbf{1 . 3 5 E - 0 2}$ & $\mathbf{2 . 6 3 E - 0 3}$ & $\mathbf{2 . 1 6 E - 0 2}$ & - & $\mathbf{7 . 0 0}$ \\
\hline
\end{tabular}


Table 11

Break-up of energy and GHG-intensities for Storm van Leeuwen and Smith (2005) (final disposal)

\begin{tabular}{llllll}
\hline Types of waste & Thermal & Electrical & \multicolumn{2}{c}{ Total primary energy } & \multicolumn{2}{c}{ GHG } \\
& {$[\mathrm{kWh} t \mathrm{kWh}]$} & {$[\mathrm{kWh} / \mathrm{kWh}]$} & {$\left[\mathrm{kWh} / \mathrm{kWh} h_{e}\right]$} & $\%$ & {$\left[\mathrm{~g} \mathrm{CO}_{2} / \mathrm{kWh}\right]$} \\
\hline Fuel elements & $9.15 \mathrm{E}-03$ & $1.26 \mathrm{E}-03$ & $1.25 \mathrm{E}-02$ & $25.53 \%$ & 2.47 \\
Operational waste & $1.65 \mathrm{E}-02$ & $3.23 \mathrm{E}-03$ & $2.51 \mathrm{E}-02$ & $51.18 \%$ & 4.45 \\
Depleted uranium & $9.43 \mathrm{E}-03$ & $5.34 \mathrm{E}-04$ & $1.09 \mathrm{E}-02$ & $22.11 \%$ & 2.54 \\
Waste from enrichment & $4.58 \mathrm{E}-04$ & $4.62 \mathrm{E}-05$ & $5.81 \mathrm{E}-04$ & $1.18 \%$ & 0.12 \\
Total & $\mathbf{3 . 5 5 E - 0 2}$ & $\mathbf{5 . 0 7 E - 0 3}$ & $\mathbf{4 . 9 1 E - 0 2}$ & - & $\mathbf{9 . 5 9}$ \\
\hline
\end{tabular}


Table 12

Greenhouse gas intensity for a variation of the fuel mix

\begin{tabular}{|c|c|c|c|c|}
\hline $\begin{array}{l}\text { GHG-intensity } \\
{\left[g \mathrm{CO}_{2} / \mathrm{kWh}_{e}\right]}\end{array}$ & Coal economy & $\begin{array}{l}\text { European mix and } \\
\text { oil }\end{array}$ & $\begin{array}{l}\text { European mix and } \\
\text { natural gas }\end{array}$ & $\begin{array}{l}\text { Nuclear and } \\
\text { burning oil }\end{array}$ \\
\hline Lenzen et al. (2006) & 57.7 & 38.7 & 32.3 & 28.3 \\
\hline $\begin{array}{l}\text { Storm van Leeuwen and Smith } \\
(2005) \text { - soft ore } 0.15 \%\end{array}$ & 236.0 & 158.9 & 132.4 & 117.2 \\
\hline $\begin{array}{l}\text { Storm van Leeuwen and Smith } \\
(2005) \text { - hard ore } 0.01 \%\end{array}$ & 797.8 & 509.1 & 432.8 & 337.4 \\
\hline
\end{tabular}


Table 13

Energy use and greenhouse gas emissions from Torfs et al. (1998) per mg U enriched

\begin{tabular}{lllllll}
\hline Energy use & $\begin{array}{l}\text { Fossil fuel } \\
(\mathrm{MJ} / \mathrm{mg})\end{array}$ & $\begin{array}{l}\text { Electricity } \\
(\mathrm{MJ} / \mathrm{mg})\end{array}$ & $\begin{array}{l}\text { Losses } \\
(\mathrm{MJ} / \mathrm{mg})\end{array}$ & $\begin{array}{l}\text { Precombustion } \\
\text { energy } \\
(\mathrm{MJ} / \mathrm{mg})\end{array}$ & $\begin{array}{l}\text { Total primary } \\
\text { energy use } \\
(\mathrm{MJ} / \mathrm{mg})\end{array}$ & $\begin{array}{l}\text { Greenhouse gas } \\
\text { emissions } \\
\left(\mathrm{g} \mathrm{CO}_{2} \text {-eq./mg }\right)\end{array}$ \\
\hline $\begin{array}{l}\text { Mining and } \\
\text { milling }\end{array}$ & $4.33 \mathrm{E}-03$ & $0.00 \mathrm{E}+00$ & $0.00 \mathrm{E}+00$ & $5.44 \mathrm{E}-04$ & $4.89 \mathrm{E}-03$ & $2.97 \mathrm{E}-01$ \\
Conversion & $5.85 \mathrm{E}-03$ & $3.10 \mathrm{E}-04$ & $0.00 \mathrm{E}+00$ & $8.88 \mathrm{E}-04$ & $7.56 \mathrm{E}-03$ & $3.73 \mathrm{E}-01$ \\
Enrichment & $1.57 \mathrm{E}-04$ & $2.33 \mathrm{E}-02$ & $0.00 \mathrm{E}+00$ & $1.79 \mathrm{E}-03$ & $7.69 \mathrm{E}-02$ & $6.32 \mathrm{E}-01$ \\
Fuel fabrication & $8.17 \mathrm{E}-05$ & $8.17 \mathrm{E}-05$ & $0.00 \mathrm{E}+00$ & $2.88 \mathrm{E}-05$ & $3.30 \mathrm{E}-04$ & $1.82 \mathrm{E}-01$ \\
Transport & $9.06 \mathrm{E}-05$ & $0.00 \mathrm{E}+00$ & $0.00 \mathrm{E}+00$ & $9.91 \mathrm{E}-06$ & $1.01 \mathrm{E}-04$ & $7.77 \mathrm{E}-03$ \\
\hline Total & $1.05 \mathrm{E}-02$ & $2.37 \mathrm{E}-02$ & $1.94 \mathrm{E}-04$ & $3.26 \mathrm{E}-03$ & $8.46 \mathrm{E}-02$ & $1.33 \mathrm{E}+00$ \\
\hline
\end{tabular}

